Boletim IG. Instituto de Geociências, USP, V. 6: 21-32, 1975

\title{
SOBRE OS DOLOMITOS E O PROCESSO DA DEDOLOMITIZAÇĀO NA FORMAÇĀO IRATI (PERMIANO) DO ESTADO DE SĀO PAULO
}

\author{
por \\ Sérgio Estanislau do Amaral \\ Departamento de Geologia Geral
}

\begin{abstract}
Dolomitization of carbonate rocks of Irati Formation (Permian) from São Paulo State is studied in the present paper. Outcrop samples as well as drilling ones are almost always made up of dolostones, either pure or slightly calcitic, independent of texture or structure. These facts indicate that the idea of syngenetic dolomitization is correct. Several different structures confirm that this process preceeded the complete diagenesis of carbonatic sediments. The phenomenon resulted of the refluxion of highly concentrated and dense brines whose $\mathrm{Mg} / \mathrm{Ca}$ relation was highly increased. These brines flowed slowly from the margins toward the center of the depositional basin. The carbonate rocks show higher calcite content in the occurrences affected by diabase sills, whose high temperature of intrusion associated with heated aqueous vapor promoted the dedolomitization phenomenon. The magnesium so expelled was probably incorpo rated in montmorillonite, the main clay mineral of the shales just above the dolomitic basal stratum.
\end{abstract}

RESUMO

$\mathrm{O}$ presente estudo trata do problema da dolomitização das rochas carbonáticas da Formação Irati do Estado de São Paulo. Tanto as amostras de superfície como as de sondagens constituem-se quase que exclusivamente de dolomitos, ora puros, ora ligeiramente calcíticos, independente da textura ou da estrutura, fatos que vêm a favor da dolomitização singenética. Diversas estruturas comprovam que o processo verificou-se antes da diagênese total dos carbonatos. $\mathrm{O}$ mecanismo da metassomatose resultou da percolação de soluções hipersalinas mais densas onde a relação $\mathrm{Mg} / \mathrm{Ca}$ foi aumentada em relação à original. Essas soluções refluiam lentamente das margens para o centro da bacia. As rochas carbonáticas se apresentam mais calcíticas nas ocorrências afetadas pelos sils de diabásio, cujo calor associado a emanações aquosas superaquecidas promoveram o fenômeno da dedolomitização. O magnésio expulso por esse processo deve ter sido incorporado à montmorillonita, principal argilo-mineral dos folhelhos situados logo acima do banco basal dedolomitizado.

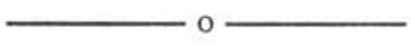

\section{INTRODUÇÃO}

No dizer de Ingerson (1962) o problema da dolomitização é um dos mais fascinantes, bem como, um dos mais importantes da Geoquímica. A par da importância geoquímica e 
geológica é grande a importância econômica, pois, graças ao aumento da porosidade secundária dos dolomitos, esses podem constituir excelentes rochas reservatórias para o petróleo. Além disso, é grande a aplicação industrial dos dolomitos, que por sua vez, podem ter relação direta com o fenômeno da mineralização, fato que decorre da possibilidade das soluções mineralizantes poderem transportar o magnésio ativo na metassomatose. A importância desse tema é patenteada pelo imenso acervo de trabalhos de pesquisa a esse respeito, datando os mais antigos de mais de um século. Dos trabalhos antigos merece destaque o de Van Tuyl (1916), notável pela acuidade nas observações de campo e de gabinete. Transcreve ainda minucioso histórico dos trabalhos pioneiros, sendo o mais antigo deles atribuído a Von Buch, escrito em 1822, onde são estudados os dolomitos do Tyrol. Daí por diante muitas dezenss de trabalhos foram publicados, sendo que a melhor síntese a respeito do complexo problema deve-se a Friedman e Sanders (1967). Lippman (1973) menciona as principais monografias a respeito da dolomitização, dentre as quais destaca-se o trabalho de Fairbridge (1957), que muito embora não dê a resposta definitiva ao problema, trata pormenorizadamente do quimismo e das condições geológicas, apresentando ainda ampla e atualizada bibliografia. Sobre a solubilidade da dolomita (assunto controvertido, havendo grandes discrepâncias entre os resultados dos diversos estudiosos), bem como, das condições hipotéticas da sua precipitação, deve ser citado o trabatho de Hsu (1967), que trata do problema referente às condições de equilíbrio e da termodinâmica do sistema $\mathrm{Ca}^{2}+, \mathrm{Mg}^{2}+, \mathrm{CO}_{3}{ }^{2-}$, $\mathrm{H}+, \mathrm{OH}^{-}$e $\mathrm{H}_{2}{ }^{0}$.

Muito embora seja antigo o problema da dolomitização, como já foi mencionado, faz apenas 10 anos que descobriram a dolomita em vias de formação em sete localidades, a saber: ilha Bonaire (situada a cerca de $230 \mathrm{~km}$ a NW de Caracas, no mar das Antilhas), estudada por Deffeyes, Lucia e Weyl (1965); ilha de Andros, nas Bahamas, situada $300 \mathrm{~km}$ a SE do extremo sul da península de Flórida, estudada por Shinn, Ginsburg e Lloyd (1965); lado oeste da península de Qatar, situada no extremo sul da margem ocidental do Golfo Pérsico, estudada por Illing, Wells e Taylor (1965); em lagos costeiros, limitados por dunas em áreas desérticas - com pluviosidade anual em torno de $40 \mathrm{~cm} /$ ano - da Austrália meridional, estudados por Alderman (1965); em mangues existentes nas costas de Qeensland, Austrália, sob a forma de concreções centimétricas situadas a cerca de meiometro de profundidade, junto a argilas siltosas. Trata-se de uma protodolomita (mal cristalizada) associada a calcita pouco magnesiana, sendo essa ocorrência estudada por Cook (1973). A literatura menciona ainda a formação de dolomita supostamente primária no Grande Lago Salgado, E.U.A., e no lago Balkash, Rússia, casos mencionados por Ingerson (1962). Nessas ocorrências que acabamos de mencionar verificam-se diversas condições, sobretudo climáticas e topográficas, propícias à evaporação intensa, o que determina a precipitação do cálcio sob a forma de sufatos, e um aumento considerável na relação $\mathrm{Mg} / \mathrm{Ca}$, que costuma atingir o valor de 30:1, podendo, em certos casos chegar até 100:1. Tal se deve à elevada solubilidade dos sais de magnésio, que perduram em solução mesmo após a intensa evaporação das águas portadoras dos referidos sais, sejam de origem marinha ou continental. Nas ocorrências que acabamos de mencionar ficou patenteada a substituição metassomática da calcita previamente formada pela dolomita, graças à percolação das soluções hipersalinas altamente magnesianas nosinterstícios da lama calcítica microcristalina. $\mathrm{O}$ aumento da superfície de contato facilita a reação que transforma a calcita em dolomita. Tudo indica tratar-se de um processo lento, secular, pois, as dolomitas mais jovens datam de 6 séculos, enquanto que outras atingem a pouco mais de 3 milênios. Tais datações foram realizadas por meio do 
carbono 14.

Apesar dessas descobertas todas e dos inúmeros estudos modernos e meticulosos, ainda perduram muitos problemas a serem estudados. Um deles se refere à síntese da dolomita sob condições normais de pressão e temperatura, até agora não realizada. Um segundo problema consiste na raridade de dolomitos no Jurássico e no Cretáceo, fato citado por Hatch e Rastall (1952), para o qual não encontramos explicações em toda a bibliografia consultada.

Mais complexo ainda é o estudo dos dolomitos antigos, dada a possibilidade do fenômeno realizar-se longo tempo após a deposição e diagênese de calcários calć́ticos, ou seja, dolomitização tardia, epigenética. Há muitos decênios os antigos já perceberam a relação dos dolomitos com ambientes mais rasos, mais próximos das áreas continentais, bem como, a sua associação mais ou menos frequente com os evaporitos. Ingerson (1962) afirma, muito a propósito, que são de grande impor- tância os dados de detalhe, como as estruturas, as texturas, e a distribuição das zonas dolomitizadas, ao lado dos estudos já elaborados referentes à quantificação entre dolomitos e calcários, bem como, à sua distribuição geográfica. Mais adiante o mencionado autor menciona a importância do estudo dos elementos traços existentes nos calcários e nos dolomitos, destacando-se entre eles o estrôncio, como será visto mais adiante.

Quando estudamos os aspectos geologicos e petrológicos de toda a Formação Irati no Estado de São Paulo (Amaral, 1971), supusemos encontrar feições nas estruturas de detalhe que pudessem esclarecer o processo da formação dos dolomitos, bem como, em que época se processou, cedo ou tarde ou ambos, em relação à deposição dos carbonatos. Não cogitamos da precipitação direta da dolomita, que é um fenômeno raro e duvidoso, discutido e analisado por Ingerson (1962). Quando nos referimos à dolomitização primária pretendíamos dizer da época concomitante à da sedi-

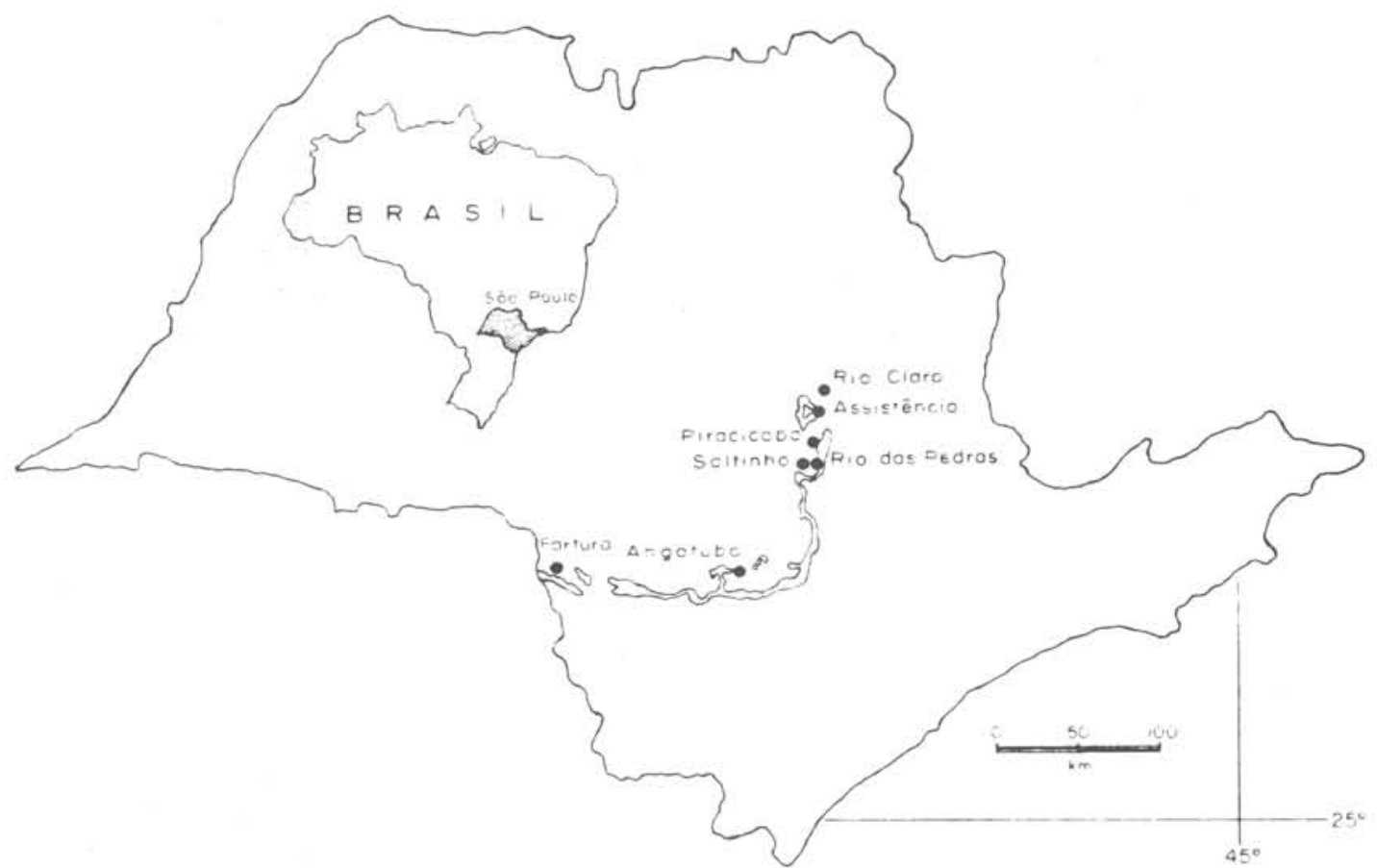

Figura 1 - Área de ocorrência da Formação Irati no Estado de São Paulo, com a localização dos municípios e localidades mencionados no texto. 
mentação, antes de terem-se completado os fenômenos diagenéticos dos carbonatos, mas não da precipitação direta da dolomita.

\section{DADOS EXPERIMENTAIS}

Ao estudarmos o processo da dolomitização da brecha intraformacional existente no banco basal da Formação Irati, o que foi feito pela imersão de fatias decimétricas serradas e polidas em solução de alizarina, observamos que os fragmentos da brecha adquiriam coloração diferente da matriz, o que nos levou a uma conclusão errônea, parecendo verificarse a coexistência pretérita de lâminas calcíticas junto a uma matriz dolomítica. Na realidade, o que se coloria de vermelho, aparentando ser calcítico, era um dolomito mais poroso, que reagia positivamente ao corante graças à maior superfície de contato. Fato análogo verificouse ao analisarmos as camadas constituídas de lâminas milimétricas, que se mostravam alternadamente calcíticas e dolomíticas, sem contudo ser o caso. Tratava-se, igualmente, de uma falsa coloração produzida pelas lâminas mais porosas. Esse mesmo resultado enganoso se obtém com o método da solução aquecida de nitrato de prata a $10 \%$ e posterior adição de cromato de potássio. As partes mais porosas também reagem positivamente, adquirindo uma coloração castanha avermelhada igual à da calcita, falseando os resultados. Esse assunto foi objeto de uma nota sobre uma técnica que adotamos fazendo uso da alizarina em dolomitos porosos e de granulação fina, não em corte, mas sobre o material finamente pulverizado (Amaral, 1974). Foram esses os motivos pelos quais retomamos o trabalho referente à dolomitização das rochas carbonáticas da Formação Irati, tendo em vista detalhar a distribuição espacial, tanto na horizontal como na vertical, dos dolomitos do banco e das camadas rítmicas. Fizemos uso das amostras já coletadas no decorrer dos trabalhos anteriores, bem como, procedendo a novas amostragens mais porme- norizadas.

Inicialmente executamos quatro amostragens detalhadas em três pedreiras próximas à vila de Saltinho. O espaçamento vertical entre as amostras variou de $5 \mathrm{~cm}$ até um máximo de $30 \mathrm{~cm}$, dependendo da maior ou menor homogeneidade das camadas.

As duas primeiras amostragens foram feitas na pedreira do Maluf, situada poucos quilômetros a SSW de Saltinho, localidade denominada Bairrinho. A distância entre as duas primeiras é de 50 metros. Uma terceira amostragem foi feita a $1,5 \mathrm{~km}$ a sudoeste das primeiras, na pedreira do Tozzo, e a quarta, a quase $2 \mathrm{~km}$ a nordeste das duas primeiras, na pedreira da Fazenda Ouro Preto. As camadas rítmicas foram amostradas uma por uma até uma altura de 6 metros acima do topo do banco basal. Tal foi executado na pedreira do Maluf, onde as exposições são mais completas. Todas as amostras colhidas nos dois primeiros perfis foram cortadas em serra de diamante perpendicularmente à estratificação, e submetidas à solução de alizarina por imersão. Obtidas as cores avermelhadas ora muito intensas, ora pouco, ora isentas de coloração, cores essas distribuídas sempre de modo regular, obedecendo ao plano da estratificação, prodecemos a coleta cuidadosa das partes diferentemente coloridas por meio de um estilete afiado e ponteagudo, com a finalidade de testar a validade do método da coloração por imersão em alizarina. Muitas análises foram repetidas por diversos processos diferentes, não tendo sido encontradas discrepâncias entre elas. Na maior parte das amostras foram dosados o $\mathrm{Ca} 0$ e o $\mathrm{Mg} 0 \mathrm{de}$ diversas maneiras, pela titulação, pelo método convencional gravimétrico e pela absorção atômica. Muitas amostras foram analisadas pela difratometria, pela radiação infravermelha e ainda pela análise térmica diferencial. Algumas análises por titulação foram realizadas no Instituto de Petrografia Sedimentar de Göttingen, Alemanha, e as demais na Universidade de São 
Paulo. Procedemos ainda à dosagem do estrôncio de cinco amostras pertencentes às primeiras amostragens.

Como já foi mencionado, todas as lâminas e todos os fragmentos da brecha intraformacional que se tornaram avermelhados ou ligeiramente avermelhados, parecendo muito calcíticos ou menos calcíticos, sendo que muitos aparentavam ser pouco dolomíticos, eram na realidade dolomitos puros ou quase puros, sendo muito pequeno o excesso de $\mathrm{Ca} 0$ nos quase puros. Graças à nova técnica que adotamos e descrevemos na nota mencionada poucas linhas atrás, pudemos verificar em pouco tempo e com grande facilidade, que predomina largamente o dolomito. Verificamos ainda que as amostras da brecha são sempre dolomíticas, quer na matriz, quer nos fragmentos, e que as variedades laminadas constituem-se de lâminas dolomíticas compactas ou mais porosas. Dada a facilidade e rapidez, ensaiamos também as amostras coletadas nos demais Estados, verificando que a calcita é um mineral relativamente raro na Formação Irati. Predominam largamente os dolomitos, por vezes ligeiramente calcíticos, quer no banco basal, quer na zona rítmica. Fazem exceção algumas lentes carbonáticas do Irati do Rio Grande do Sul, que se mostraram mais calcíticas nas ocorrências situadas na região de São Gabriel. As amostras de Pantano Grande mostraram-se mais dolomíticas, fato merecedor de um estudo mais pormenorizado. Nos Estados de Santa Catarina e Paraná parece predominar o mais dolomítico. $\mathrm{O}$ mesmo pode ser dito em relação as amostras de sondagens. Todas elas revelaram-se dolomíticas, inclusive uma amostra de Dourado, MT, a 1.843 metros de profundidade. As únicas rochas carbonáticas mais calcíticas do que dolomíticas, existentes na Formação Irati, são aquelas afetadas pelo metamorfismo térmico provocado pelas instruções de diabásio, assunto a ser discutido adiante.

Foi dosado o estrôncio de 5 amostras co- letadas nas primeiras amostragens, tendo sido usado o método da fluorescência de raios $\mathrm{X}$. $\mathrm{O}$ teor encontrado revelou-se um pouco acima do normal. Segundo Bausch (1968) os dolomitos possuem até $100 \mathrm{ppm}$ de $\mathrm{Sr}$, daí para menos, enquanto que os valores que encontramos são de 500 a 750 ppm. Se as impurezas argilosas fossem abundantes junto ao resíduo insolúvel dos dolomitos, estas poderiam explicar tal excesso de estrôncio, mas isso não ocorre. A grande porcentagem pode ser explicada pela concentração anormalmente elevada dos sais das águas estagnadas que refluiam graças à sua maior densidade, como será discutido adiante. É provável que a precipitação original tenha sido de aragonita, mineral que pode conter até 10.000 ppm de estrôncio, graças à similaridade da sua estrutura com a da estroncianita, carbonato de estrôncio rômbico, com estruturas similares. Com a recristalização da aragonita em calcita o estrôncio é expulso, podendo ser incorporado por adsorção a argilo-minerais. Sendo esses muito escassos junto à fração insolúvel dos dolomitos do Irati, de um modo geral, acreditamos que o estrôncio ocorra sob a forma de solução sólida, não sabemos de que natureza, se intersticial ou por substituição. Podemos ainda supor, em base do trabalho de Kinsman (1969), que a lama dolomítica originária possuia baixa permeabilidade. Caso contrário, soluções posteriores lixiviariam o excesso do citado elemento. Podemos supor também que foram restritas as condições de percolação de águas vadosas após a diagênese dos carbonatos e folhelhos, pois, dar-se-ia igualmente a perda do estrôncio sob essas condições.

Além dos ensaios mencionados procedemos também à observação de seções delgadas previamente coloridas com alizarina, tanto dos dolomitos normais, de granulação fina, do banco basal e da zona rítmica (até $6,5 \mathrm{~m}$ acima do topo do banco), como também das rochas metamorfizadas pelo diabásio. Essas últimas são as únicas mais calcíticas, como acabamos de mencionar, enquanto que todas as demais são 
representadas por dolomitos ora puros, ora muito pouco calcíticos, independendo da granulação (mais comumente ao redor de 5 a 10 mícrons) ou da textura. Fato análogo é verificado nas amostras ricas em carapaças de Liocaris (crustáceo de poucos milímetros de tamanho, por vezes muito abundantes na Formação Irati, chegando a constituir camadas decimétricas), bem como, nos tipos calcareníticos, constituídos de minúsculas pelotas carbonáticas ou prováveis oólitos. Ocasionalmente algumas lâminas adquirem ligeira coloração avermelhada, pelo efeito somatório de um início de coloração, sem que se possa individualizar a calcita. Este mineral não deve ser totalmente ausente, mas raro, como regra geral. As análises apresentadas por Paolielo (1972) mostram um ligeiro excesso em $\mathrm{CaO}$ em muitas das amostras, enquanto que em outras as proporções entre cálcio e magnésio são as mesmas da dolomita. Ao investigarmos as localidades apresentadas por Paolielo, correspondentes às análises com teor mais elevado em $\mathrm{Ca} 0$, verificamos a coincidência com os locais afetados pelas intrusర̃es de diabásio. Uma das ocorrências maıs ricas em calcita situa-se próxima a Rio das Pedras, onde fizemos dois perfis e ensaios com alizarina controlados por análises químicas. Essas vieram comprovar a validade do método que empregamos (Amaral, 1974), ficando dessa maneira patenteado o processo da dedolomitização provocada pela influência do diabásio, assunto a ser tratado adiante. Fato idêntico constatamos para duas ocorrências paranaenses, situadas entre Joaquim Távora e Santo Antônio da Platina.

A fim de verificarmos se os fosfatos tricálcicos dos ossos dos Stereosternum foram também afetados pelas soluções magnesianas dolomitizantes, procedemos à análise de algumas costelas do referido réptil previamente examinadas ao microscópio petrográfico. Esse exame teve a finalidade de excluir eventuais ossos carbonáticos, que são bem mais raros. Predominam largamente os fosfáticos, fossilizados por conservação. $\mathrm{O}$ teor de $\mathrm{MgO}$ é baixo, de apenas $0,5 \%$, provavelmente motivado por infiltrações carbonáticas nos canais de Havers, que são bem conservados e muito comumente preenchidos por betume. (Amaral, 1971).

\section{O PROCESSO DA DOLOMITIZAÇÃO E SEU AMBIENTE PROVÁVEL}

Nas quatro localidades mencionadas anteriormente, onde a dolomita acha-se em vias de formação, verificam-se diversas condições que se enquadram bem ao suposto ambiente de deposição do Irati, tais como, salinidade elevada, $\mathrm{pH}$ alcalino, número restrito de espécies viventes e relevo suave. Com exceção do trabalho de Badiozamani (1972), que advoga a mistura de água do mar com água doce, mistura essa, segundo ele, ativa na substituição do cálcio pelo magnésio (o mencionado autor estudou os dolomitos ordovicianos de Wisconsin), todos os demais autores são unânimes ao darem ênfase ao valor elevado da salinidade associado a condições topográficas especiais, responsáveis pela evaporação intensa e consequente concentração dos solutos. Precipitando-se o cálcio sob a forma de sulfatos, os íons de magnésio perduram em solução, e com isso, aumenta a relação $\mathrm{Mg} / \mathrm{Ca}$. Alderman (1965) determinou valores entre 20 e 100 para essa relação existente nos lagos da costa sudeste da Austrália, onde a dolomita, ao lado de outros carbonatos mal cristalizados, acha-se em vias de formação. A ideia da alta salinidade das águas em que se depositou o Irati é antiga, já aventada por Washburne (1930), que relacionava a escassez de fósseis à alta salinidade. A relação dolomitos com a diminuição de fósseis constitui uma observação antiga, mencionada por diversos estudiosos, entre eles, E.T. Degens (in Ingerson, 1962), que afirma que quanto mais salino o ambiente, maior a concentração dos fons de magnésio e menor o indice de vida, fatos que se enquadram bem para a Formação Irati e já comentados pelo Autor (Amaral, 
1971). Ao lado da salinidade elevada é imprescindível a existência de poros que permitam a percolação das soluções concentradas mais densas, que fazem deslocar a água conata menos densa, cujo principal papel é o de remover o cálcio formado na reação dolomitizante, segundo a reação:

$2 \mathrm{CaCO}_{3}$ (sólido) $+\mathrm{Mg}^{2}+=\mathrm{CaMg}$ $\left(\mathrm{CO}_{3}\right) 2$ (sólido) $+\mathrm{Ca}^{2}+$ (Lippmann, 1973).

Durante a fase inicial da deposição carbonática deve ter havido condições de porosidade e permeabilidade favoráveis à percolação dessas águas salinas, mormente durante a formação dos calcarenitos ricos em fragmentos de Liocaris ou de oblitos, pelotas, fragmentos brechados, e outros. Posteriormente o meio tornar-seia impermeabilizado pela lama calcária fina,já dolomitizada, existente entre os fragmentos mencionados. Essa impermeabilização seria responsável pela retenção parcial do estrôncio, como já foi mencionado. Quanto aos micritos homogêneos e compactos, que formam a maioria dos dolomitos do Irati, acreditamos que a matéria orgânica existente na fase inicial da lama tenha influído no sentido de aumentar a permeabilidade, graças à produçaõ de gases que se formam do decorrer dos processos de fermentação anaeróbica. Praticamente todos os dolomitos apresentam o odor característico quando moídos recentemente, o que indica a existência generalizada da matéria orgânica, que deve ter perdurado durante longo tempo, dadas as condições redutoras do ambiente.

Quanto às condições fisiográficas responsáveis pela dolomitização existem diversos modelos que se acham bem expostos e sintetizados esquematicamente por Badiozamani (1972). De todos eles o que mais se enquadra no caso do Irati é o modelo proposto por Adams e Rhodes (1960) para dolomitos permianos. do Texas. Segundo esses autores as zonas dolomitizadas acham-se delimitadas por barreiras que permitiram a formação de áreas isoladas em ambientes rasose em clima quente, favorecendo uma evaporação intensa e um cònsequente aumento na salinidade e densidade, como já mencionamos. A calcita recém formada, cuja granulação costuma ser de poucos mícrons, é mais facilmente atacada pelas soluções magnesianas em refluxo, no decorrer de poucos séculos, se as condições forem análogas às verificadas por Deffeyes et al. (1965) para a ilha Bonaire, onde a dolomita recém formada foi datada pelo método do ${ }^{14} \mathrm{C}$. A única diferença consiste na inexistência de barreiras separando do mar aberto, mas sim, de um ambiente fechado, raso, sujeito a um regime de intensa evaporação e ligado ao mar, que supria a água evaporada, assunto já referido anteriormente (Amaral, 1971).

Quanto à época em que se verificou o fenômeno, não resta a menor dúvida de ser logo após a sedimentação. Ingerson (1962) menciona diversos autores, destacando-se Cloud e Barnes, que dão ênfase ao fato dos dolomitos possuirem na maioria das vezes uma granulação muito fina, geralmente de poucos mícrons, fato perfeitamente compatível com a geração penecontemporânea, e que se enquadra muito bem com a Formação Irati no que diz respeito ao fenômeno da dolomitização. Segundo Hatch e Rastall (1952) e diversos outros estudiosos, o dolomito secundário exibe romboedros formados pela recristalização da calcita atacada pelas soluções magnesianas, sendo diminuído o volume, dando origem a uma porosidade secundária que pode chegar a $15 \%$. Com a recristalização as estruturas primárias são obliteradas e o processo costuma ser irregular, incompleto, relacionado a fraturas ou falhas, ou ainda à estratificação, pelo fato de constituírem zonas propícias à percolação dos fluidos. Nenhum desses aspectos são verificados na Formação Irati. Ocasionalmente ocorrem lâminas de granulação mais grossa contendo raros e esparsos romboedros de dolomita de 100 a 150 mícrons de tamanho, lâminas essas intercaladas às lâmi- 
nas dolomíticas de granulação normal, ou seja, de cerca de 6 mícrons, como valor médio. Outra evidência clara de que o processo da dolomitização processou-se antes da diagênese, na época em que a lama carbonática ainda estava no estado plástico, consiste na existência das intrusões de dolomitos (Amaral, obra citada, pag. 38) e na brecha dolomítica intraformacional. Em ambos os casos a textura é microgranular, sem apresentar o menor sinal de recristalização, e de grande uniformidade na composição, ou seja, sempre de natureza dolomítica. Muito embora a literatura descreva a formação primária da dolomita em lagos do sudeste da Austrália (Skinner et al., 1963), no Grande Lago Salgado e no Lago Balkash, na Rússia (Ingerson, 1962), julgamos mais provável a dolomitização penecontemporânea, pelo fato da dolomita primária nunca ter sido formada experimentalmente, e pelo fato de não existirem provas convincentes de que nas ocorrências mencionadas verificou-se realmente a precipitação direta do carbonato duplo de cálcio e magnésio cristalizado segundo a estrutura da dolomita. Os exames pelo raio $\mathrm{X}$ revelam sempre estruturas mal definidas, a ponto de denominarem o mineral de protodolomita.

O valor elevado do $\mathrm{pH}$ encontrado por Alderman (1965) para os lagos da Austrália, de 10,2 , vem de acordo com o que foi exposto por nós (Amaral, 1971) bem como, as condições redutoras. Quanto à temperatura, Von der Borch (1965) mediu valores que atingem 36 ? para os lagos citados do sul da Austrália, valores que concordam com os calculados por Adams e Rhodes (1960) para os dolomitos permianos do Texas. Ingerson (1962) cita diversos outros estudiosos que concordam que o processo da dolomitização requer clima quente, fato que constitui mais um argumento a favor do que afirmamos para o Irati. A abundância em répteis (Stereosternum e Mesossaurus) é perfeitamente compatível com o clima quente.

\section{$\mathrm{V}$ - O PROCESSO \\ DA DEDOLOMITIZAÇÃO}

Já nos referimos ao maior teor em $\mathrm{Ca} 0$ nos dolomitos afetados pelo calor das intrusð̄es de diabásio, chegando a dar origem a calcários dolomíticos com até $70 \%$ de calcita e $27 \%$ de dolomita, originados da dedolomitização dos dolomitos originais. Em uma das ocorrências, onde as análises apresentadas por Paolielo (1972) revelaram teor anormalmente elevado de $\mathrm{Ca} 0$, procedemos a uma segunda amostragem mais detalhada, tendo em vista a verificação da distribuição das partes mais calcíticas. Trata-se da pedreira da Lapa, do Eng. Pedro Abechian, situada a $6 \mathrm{~km}$ a SW de Rio das Pedras, onde o teor médio de $\mathrm{Ca} 0$ é de quase $40 \%$, ou seja, $10 \%$ a mais em relação aos dolomitos puros, sem considerar ainda as impurezas silicosas. Não pudemos conhecer a espessura do sil de diabásio que se encontra por baixo do Irati, pelo fato de não aflorar. Acreditamos, no entanto, que deva ser de mais de 30 metros, comparando-se com o sil de Assistência, cujos efeitos no metamorfismo foram menos intensos (não se formou a grafita, que ocorre em Rio das Pedras, e conservou em parte o betume) e a espessura local pôde ser medida, sendo de 25 metros. Procedemos a uma amostragem de 20 em 20 centímetros em dois perfis distanciados de cerca de 20 metros, sendo um deles em rocha clara, e outro em rocha quase preta, graças às impurezas expulsas pela recristalização da parte mais clara. Escolhemos três amostras de cada perfil, sendo uma delas pouco acima da base do banco, uma no meio e outra no topo, para serem analisadas quimicamente. A partir das análises químicas calculamos as porcentagens entre calcita e dolomita, sendo os seguintes os resultados obtidos:

\begin{tabular}{|c|c|c|c|c|}
\cline { 2 - 5 } \multicolumn{1}{c|}{} & \multicolumn{2}{c|}{ rocha clara } & \multicolumn{2}{c|}{ rocha escura } \\
\cline { 2 - 5 } \multicolumn{1}{c|}{} & calcita & dolomita & calcita & dolomita \\
\hline Topo & 26,5 & 67,3 & 70,5 & 27,1 \\
Meio & 22,0 & 76,5 & 10,8 & 89,0 \\
Base & 44,4 & 55,4 & 21,9 & 78,2 \\
\hline
\end{tabular}

Numa segunda pedreira situada 600 metros a WSW da primeira encontramos o valor médio 
de $56 \%$ de calcita e $43,5 \%$ de dolomita, a partir de diversas amostras coletadas aleatoriamente, pelo fato da pedreira ter sido soterrada. É provável que as amostras de Assistência sejam ainda mais calcíticas, tendo em vista as análises de Paolielo (1972) e os testes de coloração com alizarina que executamos. Deve ser lembrado que os calcários não afetados pelo diabásio, onde predominam largamente os dolomitos puros a quase puros, acham-se a pouco mais de $3 \mathrm{~km}$ afastados em relação a esses que sofreram a dedolomitização, quer para as de Rio das Pedras, quer para as de Assistência.

Em seção delgada devidamente colorida com alizarina a calcita torna-se bem visível pela coloração vermelha, sem contudo formar indivíduos isolados. Tanto a calcita como a dolomita formadas pela recristalização provocada pelo metamorfismo termal associado ao fenômeno da dedolomitização, possuem formas indefinidas, irregulares, achando-se caoticamente interpenetradas. Observando-se a extinção sob o microscópio petrográfico e logo em seguida a coloração pela alizarina, conclui-se que na maioria das vezes um indivíduo sob o ponto de vista cristalino é formado pela calcita mais dolomita irregularmente interpenetradas. Graças à recristalização o tamanho médio desses cristais mencionados aumenta para 50 mícrons, como valor médio.

Faust (1949) estudou com pormenores o problema da dedolomitização, bem como, do equilíbrio entre os solutos resultantes dos respectivos carbonatos sob diferentes condições de temperatura e pressão do $\mathrm{CO}_{2}$ em meio aquoso. Segundo o referido estudioso as rochas de granulação mais fina sofrem o processo da dedolomitização a temperaturas mais baixas, fato que se aplica bem ao nosso caso, pois, já referimos que a granulação média dos dolomitos do Irati varia de 6 a 10 mícrons. A ausência de brucita ou de periclásio é explicada emvista da solubilidade do carbonato de magnésio sob condiçбes de alta temperatura e elevada pressão de $\mathrm{CO}_{2}$. É provável que o magnésio que migrou tenha se incorporado, pelo menos em parte, aos folhelhos que se sobrepõem ao banco basal. São montmorilloníticos, com um teor de $\mathrm{Mg} 0$ de $11,6 \%$, ou seja, praticamente o dobro do teor existente nos mesmos folhelhos afastados da influência do diabásio. A existência da hidromagnesita (Amaral, 1971) nas rochas afetadas pelo metamorfismo comprova a migração do magnésio (Faust, 1949). Tanto o Mg0 como o $\mathrm{Mg}(\mathrm{OH})_{2}$ são passíveis de serem dissolvidos por águas aquecidas e aciduladas pelo $\mathrm{CO}_{2}$, dando origem ao bicarbonato de magnésio solúvel. A fig. 6 do mencionado trabalho esclarece o fenômeno por meio de um gráfico tridimensional que contém as três variáveis, a temperatura, a pressão do $\mathrm{CO}_{2}$ e a concentração do carbonato hidratado de magnésio em gramas por litro. Dada a pequena quantidade de água no magma basáltico, de apenas $0,1 \%$, segundo a literatura, acreditamos que a água ativa no presente processo tenha se originado dos sedimentos situados abaixo do Irati, ou seja, do Grupo Tubarão. $O$ sil que metamorfizou o Irati de Assistência (local onde foi encontrada a hidromagnesita e onde foi efetuada a análise química dos folhelhos) possui 25 metros de espessura, o que certamente produz uma reserva térmica suficiente para que o fenômeno tenha se processado. A fração volátil deve ter escapado totalmente através das encaixantes, pois, não ocorrem vesículas nem amígdalas no topo desse diabásio. $\mathrm{O}$ gás carbônico seria proveniente da dissociação térmica do próprio carbonato, situádo imediatamente acima da intrusiva.

$O$ processo da dedolomitização processa-se da seguinte maneira, no dizer de Faust (1949): após a intrusão magmática inicia-se a irradiação térmica através das encaixantes, bem como o escape dos voláteisatravés das fraturas $\mathrm{e}$ e das zonas mais permeáveis das encaixantes. No contato com o dolomito libera-se o gás carbônico formado junto ao contato, bem como, nos eventuais xenólitos carbonáticos, desprendendo-se juntamente com o vapor 
dágua. À medida que o magma se cristaliza aumenta a quantidade de emanações aquosas, que continuam migrando através das encaixantes. No caso de ter-se gerado o periclásio $(\mathrm{Mg0})$, verificar-se-ia a sua hidratação formando-se a brucita, que por sua vez, poderia ser dissolvida pelas próprias soluções sob condições hidrotermais.

No nosso caso, contudo, não existem evidências de dissolução, nem eventuais remanescentes de brucita. Ả pág. 819 do referido trabalho, Faust apresenta para o fenômeno as seguintes alternativas: a) a dolomita ter-se-ia dissolvido sem que houvesse uma separação de uma fase sólida, e ainda, não se verificando a reversibilidade dessa dissolução. Em outras palavras, evaporando-se o solvente não se precipita a dolomita, mas sim, somente a calcita, perdurando o carbonato de magnésio em solução. b) Numa segunda alternativa dar-se-ia a dissolução apenas da fração magnesiana, perdurando in situ o carbonato de cálcio menos solúvel. c) Finalmente, uma terceira alternativa seria a da realização de ambos os processos, ora um, ora outro, dependendo de diversas variáveis, como temperatura, pressão do gás carbônico e concentração dos solutos. Para os dolomitos do Irati, sob as condições de dedolomitização, opinamos para a segunda alternativa, tendo em vista a textura da rocha examinada em seção delgada. Já nos referimos à íntima associação dos dois minerais, calcita $\mathrm{e}$ dolomita no mesmo indivíduo (sob o ponto de vista óptico). Tudo faz crer numa dissolução parcial e incongruente, migrando os íons de magnésio das partes mais afetadas pelas soluções aquecidas. Parte desses íons dariam origem à hidromagnesita (mineral relativamente raro, encontrado até agora apenas em Assistência), parte ter-se-ia fixado nas montmorillonitas dos folhelhos da zona rítmica do Irati, sendo provável que a maior parte tenha sidolevada em solução pelas águas circulantes.

\section{CONCLUSÕES}

As rochas carbonáticas que ocorrem na Formação Irati do Estado de São Paulo, quer as aflorantes, quer as de sondagens, constituemse quase que exclusivamente de dolomitos, ora puros, ora muito pouco calcíticos. No Estado do Rio Grande do Sul ocorrem com relativa frequêencia calcários pouco dolomíticos, sem que tenham sofrido o fenômeno da dedolomitização.

$\mathrm{O}$ processo da dolomitização processou-se durante a época da sedimentação e antes da diagênese total dos carbonatos, tendo sido motivada por soluções hipersalinas mais densas que refluiam das bordas para o centro da bacia. Essas soluções, cuja principal característica é a elevada relação $\mathrm{Mg} / \mathrm{Ca}$, não afetaram os fosfatos tricálcicos que formavam os ossos dos répteis que viveram na época da deposição do Irati.

Uma das principais características inferidas para o ambiente em que se depositaram os dolomitos da Formação Irati constitui na elevada salinidade e a consequente elevada relação $\mathrm{Mg} / \mathrm{Ca}$, fato verificado em uma ou mais de uma bacia fechada, sujeita a intensa evaporação e em comunicação com o mar. $\mathrm{O}$ pH deveria ter sido elevado, o Eh negativo (condiçðes redutoras) e a temperatura elevada.

Os corpos intrusivos de diabásio promoveram o fenômeno da dedolomitização parcial e irregular dos dolomitos da Formação Irati afetados pela referida rocha. As soluções magnesianas resultantes da dedolomitização determinaram o aumento do teor em $\mathrm{MgO}$ da montmorillonita dos folhelhos situados logo acima do banco basal do Irati.

\section{AGRADECIMENTOS}

Externamos os nossos profundos e sin- 
ceros agradecimentos ao Pro. Dr. Raphael Hipolito pelo trabalho que teve de analisar quimicamente a maior parte das amostras estudadas; ao Prof. Dr. Viktor Leinz, pela leitura cuidadosa do texto e pelas sábias críticas apresentadas; ao Prof. Dr. José Vicente Valarelli, pelas análises sob as radiaçð̃es infravermelhas, bem como, pelos difratogramas elaborados; ao Prof. Dr. Marcos Berenholc, pelas análises dos elementos traços pela fluorescência de raios X; ao Prof. André Bittencourt, pelas análises térmicas diferenciais; à Dna. Elóide Maria Fuck, pelo trabatho paciente de preparar as amostras para as diversas análises; finalmente, agradeço à Fundação de Amparo à Pesquisa do Estado de São Paulo, FAPESP, pelo auxílio financeiro que permitiu a realização das diversas viagens às localidades estudadas.

\section{BIBLIOGRAFIA}

Adams, J.E. e Rhodes, M.L. (1960) - Dolomitization by seepage refluxion Am. Ass. Petr. Geol. 44, (12): 1912-1920.

Alderman, A.R. (1965) - Dolomitic sediments and their environment in the SouthEast of South Australia - Geoch. et Cosmoch. Acta, 29 1355-1365.

Amaral, S.E. do (1971) - Geologia e Petrologia da Formação Irati (Permiano) no Estado de São Paulo - Inst. Geoc., U.S.P. 2: 3-81.

Amaral, S.E. do (1974) - Nova técnica de identificação de dolomitos de granulação fina com alizarina-S - Inst. Geoc., U.S.P., 5: 29-32.

Badiozamani, K. (1972) - The dorag dolo mitization model - application to the Middle Ordovician of Wisconsin - Tese de doutoramento, Univ. Northwestern, Illinois.

Badiozamani, K. (1973) - idem - Jour. Sed. Petr., 43 (4): 965-984.

Bausch, W.M. (1968) - Outlines of distribution of strontium in marine limestones - in Recent Developments in Carbona- te Sedimentology in Central Europe, pp. 106-127, Ed. por Müller G. e Friedman, G.M., Spring-Verlag, Berlim.

Cook, P.J. (1973) - Supratidal environment and geochemistry of some recent dolomite concretions, Broad Sound, Qeensland, Australia - Jour. Sed. Petr. 43 (4): 998-1011.

Deffeyes, K.S., Lucia, F.J. e Weyl, P.K. (1965) - Dolomitization of Plio-Pleistocene Sediments by marine evaporite waters on Bonaire, Netherlands, Antilles - in Dolomitization and limestone Diagenesis, A Symposium, Soc, Econ. Paleont. and Min. Sp. Publ. no 13, Tulsa, E.U.A.

Fairbridge, R.W. (1957) - The dolomite question - in Regional Aspects of Carbonate Deposition,Soc. Econ. Paleont, and Min., Sp. Publ. 5: 125-178, Tulsa, E.U.A:

Faust, G.T. (1949) - Dedolomitization, and its relation to a possible magnesium-rich hydrothermal solution - The Am. Min., 34: 789-823.

Friedman, G.M. e Sanders, J.E. (1967) - Origin and occurrence of dolostone, in Car- 
bonate Rocks, 9A, G.U. Chilinger et al., 267-348, Amsterdam, Elsevier.

Hatch, F.H. e Rastall, R.H. (1952) - The Petrology of the Sedimentary Rocks, Thomas Murby \& Co., London, 3ạ ed.

Hsu, K.J. (1967) - Chemistry of dolomite formation - in Carbonate Rocks, ed. por Chilinger, G.V., Bissell, H.J. e Fairbridge, R.W., 169-191, Elsevier Publ. Co., N.Y.

Illing. L.V., Wells, A.J. e Taylor, J.C.M. (1965) - Penecontemporary dolomite in the Persian Gulf - in Dolomitization and limestone Diagenesis, A Symposium, Soc. Econ. Paleont. and Min. Sp. Publ. n? 13, Tulsa, E.U.A.

Ingerson, E. (1962) - Problems of the Geochemistry of Sedimentary Carbonate Rocks - Geoch. et Cosmoch. Acta, 26: 815-847.

Kinsman, D.J.J. (1969) - Interpretation of $\mathrm{Sr}+2$ concentrations in carbonate minerals and rocks - Jour, Sed. Petr., 39, (2): 486-508.

Lippmann, F. (1973) - Sedimentary Carbonate Minerals - Springer-Verlag Berlin,
228 pags.

Paolielo, P.C. (1972) - O dolomito da Formação Irati como corretivo de acidez dos solos do Estado de São Paulo - tese de doutoramento, Esc, Politécnica U.S.P.

Shinn, E.A., Ginsburg, R.N. e Lloyd, R.M. (1965) - Recent supratidal dolomite from Andros Island. Bahamas - in Dolomitization and Limestone Diagenesis, A Symposium, Soc. Econ. Paleont. and Min. Sp. Publ. n? 13, Tulsa, E.U.A.

Skinner, H.C:W.; Skinner, B.J. e Rubin, M. (1963) - Age and accumulation rate of dolomite-bearing carbonate sediments in South Australia - Science, 139: 355-356.

Van Tuyl, F.M. (1916) - New points on the origin of dolomite - Am.Jour.Sci., 42: 249-260.

Von der Borch, C. (1965) - The distribution and preliminary geochemis try of modern carbonate sediments of the Coorong area, South Australia - Geoch. et Cosmo. Acta, 29: 781-799.

Washburne, C.W. (1930) - Petroleum Geology of the State of São Paulo - Com. Geogr. Geol, Bol. 22, São Paulo, SP. 